\title{
Study Subject Nuclear Medicine Image
}

National Cancer Institute

\section{Source}

National Cancer Institute. Study Subject Nuclear Medicine Image. NCI Thesaurus. Code C115553.

A nuclear medicine image taken of a study participant for use in a clinical trial. 